\title{
Notes on Norse Finds from the East Coast of Ellesmere Island, N.W.T.
}

\section{PETER SCHLEDERMANN ${ }^{1}$}

During the 1978 and 1979 field seasons in the Bache Peninsula region on the east coast of Ellesmere Island (Schledermann, 1978), a number of artifacts mostly of European manufacture and presumably related to Norse activities was located in old Thule culture winter house ruins.

The finds were made on three sites in the study area (Fig. 1): Skraeling Island (chain mail sections, knife blades, boat rivets, iron point and copper pieces, woolen cloth), the Eskimobyen site on Knud Peninsula (barrel bottom, box section, copper piece), and Haa Island (ivory figurine). A general description of these finds, locational data, associated radiocarbon dates and material analyses are presented. Specific site maps and house localities are on file with The Arctic Institute in preparation for publication.

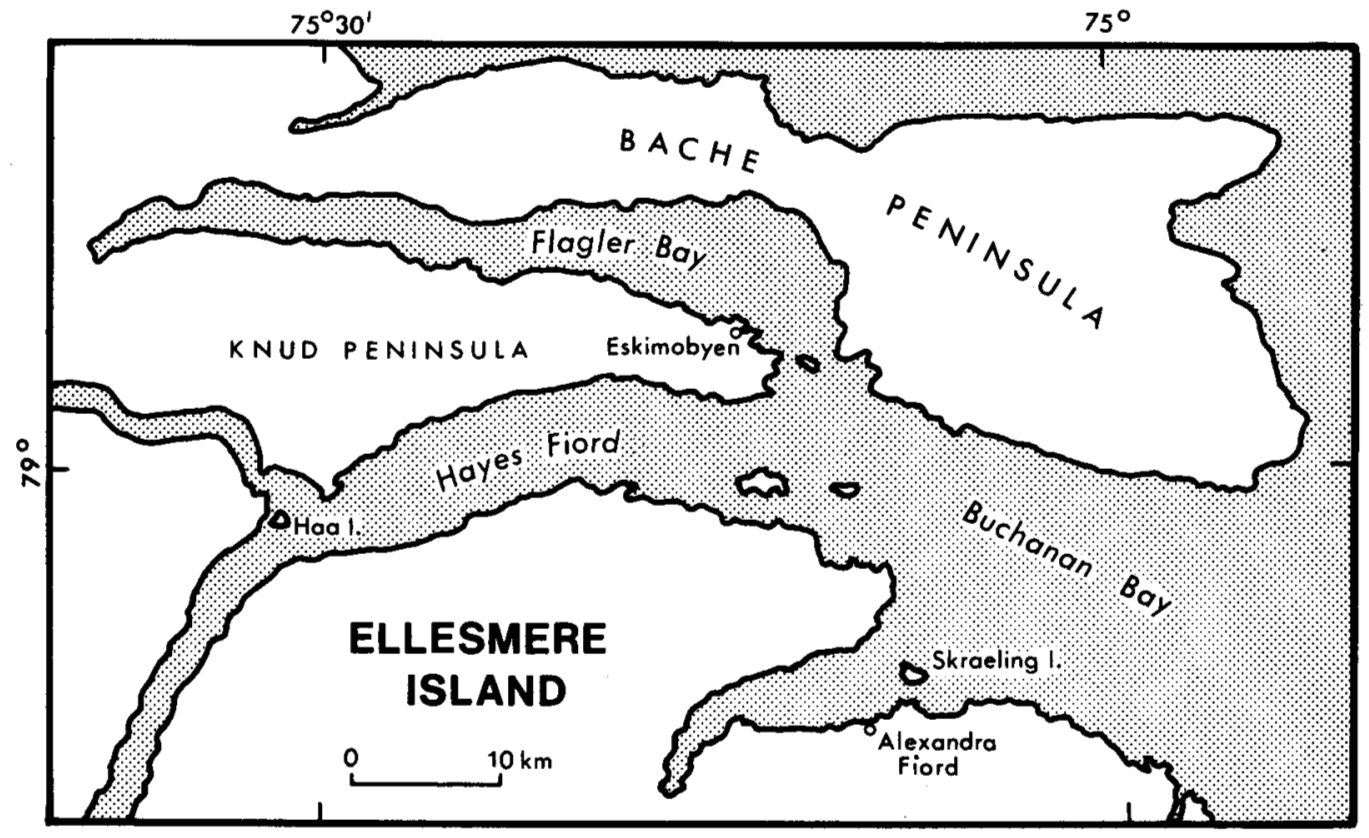

FIG. 1. The study area. 

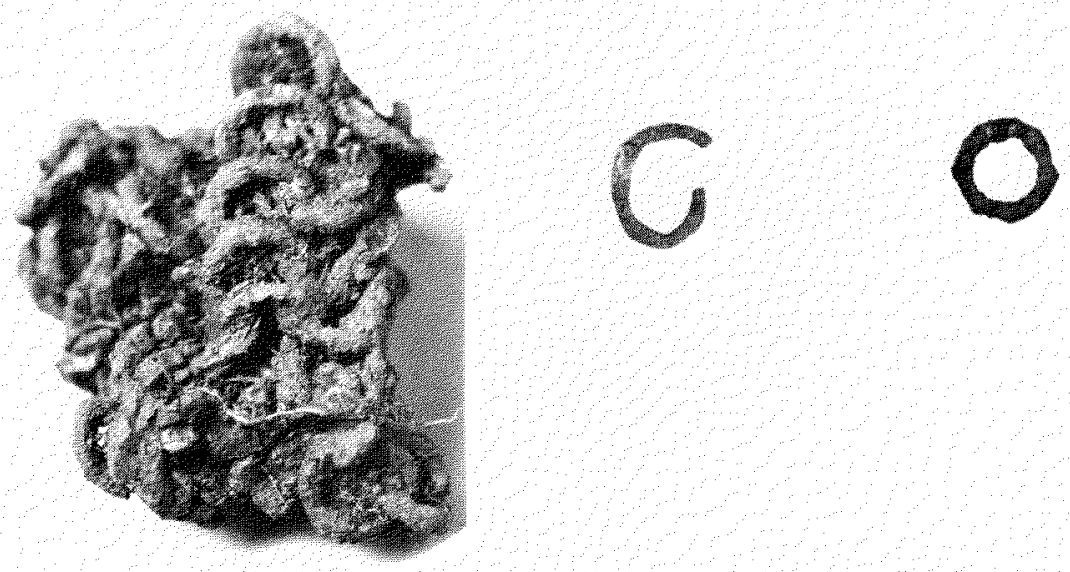

FIG. 2. a) A section of chain mail, located between 25 and $30 \mathrm{~cm}$ below top sods in house ruin 6 . The specimen was situated on a gravel floor near the passageway to a separate kitchen room and adjacent to a small stone-lined meat pit. Wood charcoal (oak) from the kitchen gave the following radiocarbon date: GX 6069, $670 \pm 110$ B.P. (C-13 corr.), or A.D. 1280. b) A single chain mail link located in the central floor area of house ruin 10. A radiocarbon assessment on willow from the floor of the dwelling gave the following result: GSC $2938,760 \pm 60$ B.P. (C-13 corr.), or A.D. 1190. c) A single chain mail link found on the gravel floor of house ruin 2.

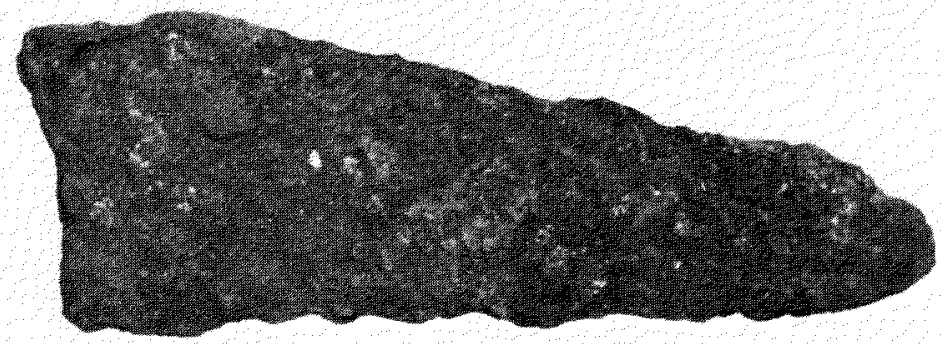

FIG. 3. An iron point or blade located on the main floor near the entrance passage of house ruin 2. An analysis of the metal gave the following results: $\mathrm{Fe} \mathrm{100.8,} \mathrm{Ni}<0.06, \mathrm{Cu}<0.19$. 

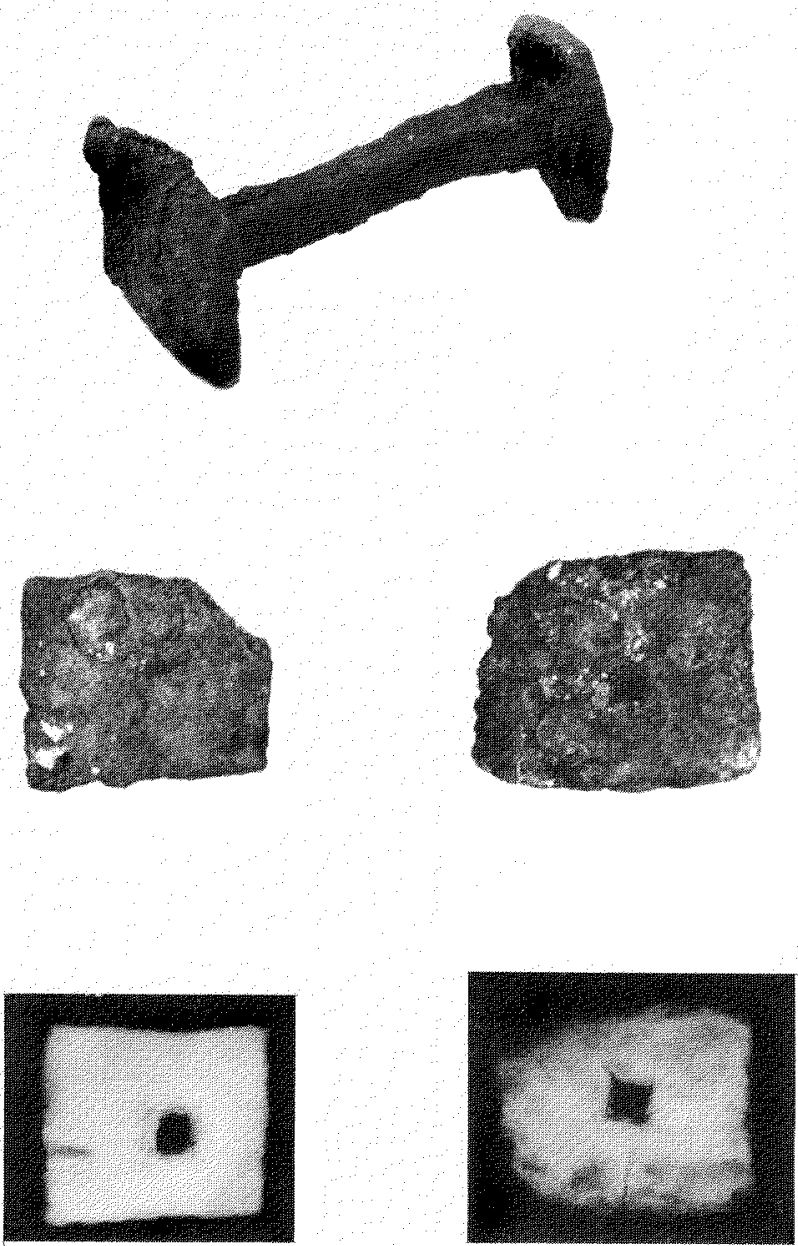

FIG. 4. a) An iron boat rivet (possibly from a viking ship) located near the bottom of a stone-lined meat pit in house ruin 6 . See date for Figure $2 a, 670 \pm 110$ B.P. b) A boat rivet (clinch nail) section found on the floor near the southwest wall of house ruin 10. See radiocarbon date for Figure $2 b$. c) This boat rivet section was located on a raised side bench along the northwest wall of house ruin 4 , a festival structure. d) and e) Radiograph pictures of Figures $4 \mathrm{~b}$ and $\mathrm{c}$, respectively, showing the square central holes in the rivet sections. 

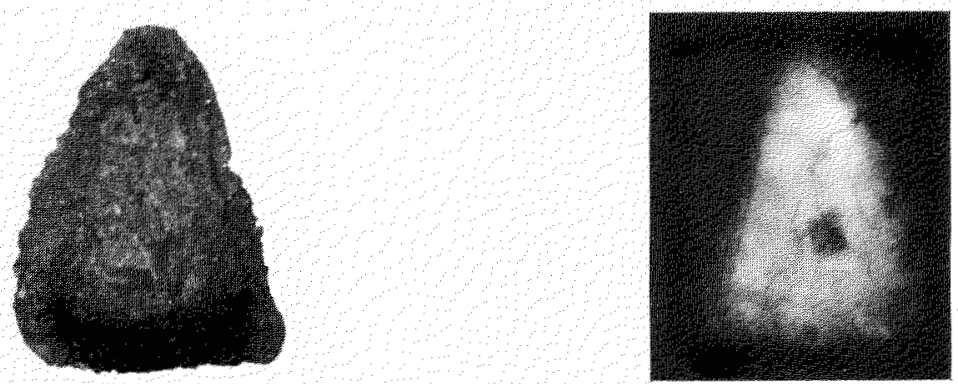

FIG. 5. a) An iron point, located between wall stones of house ruin 1 . The specimen appears to have been manufactured by altering a ship rivet section as indicated by the radiograph (b) which shows the square centre hole of the original piece.

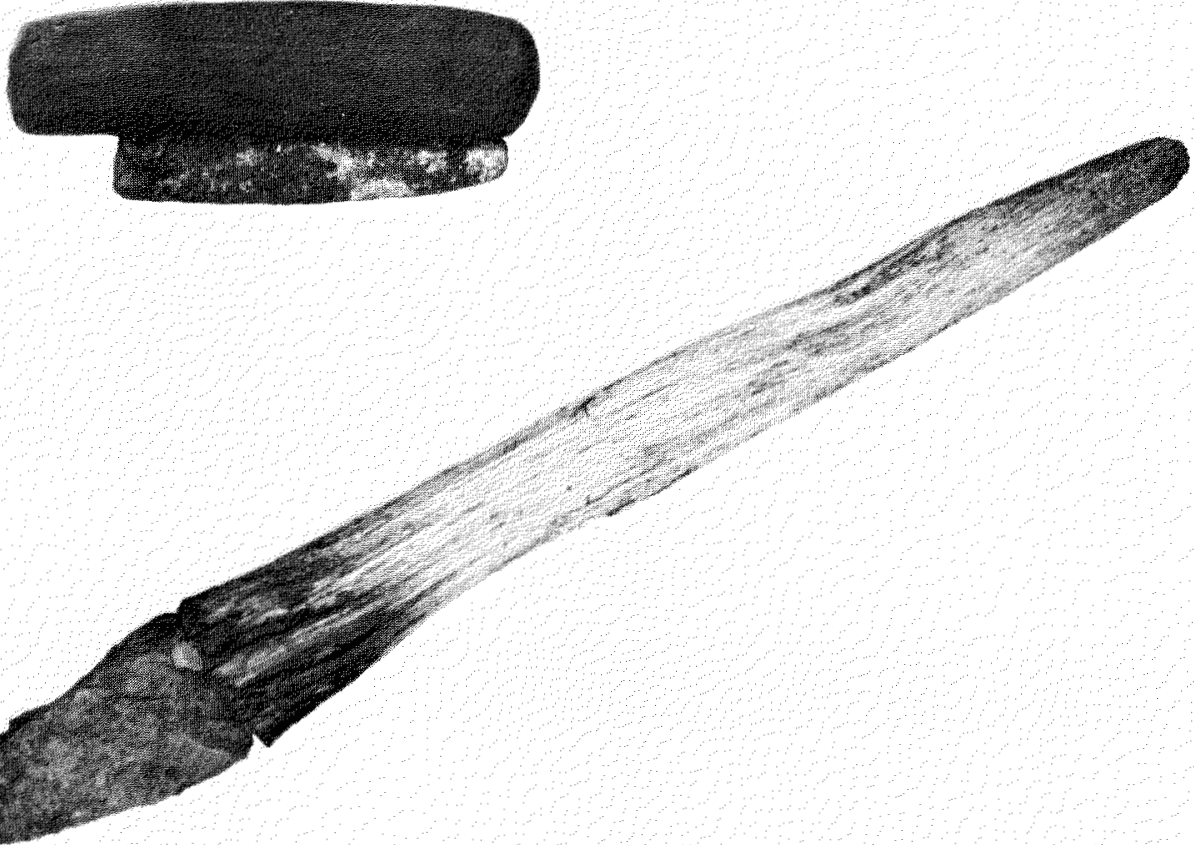

FIG. 6. a) An iron knife blade inset in a wooden handle, located in the central floor area of the festival structure, house 4. An analysis of the metal gave the following results: $\mathrm{Fe} 100.0, \mathrm{Ni}<0.06$ and $\mathrm{Cu}<0.19$. b) An iron knife blade inset in a handle of musk-ox horn. The find was made in the central floor area of house 4 and the metal analysis gave the following results: $\mathrm{Fe} 99.5, \mathrm{Ni}<0.06$ and $\mathrm{Cu}<0.19$. 

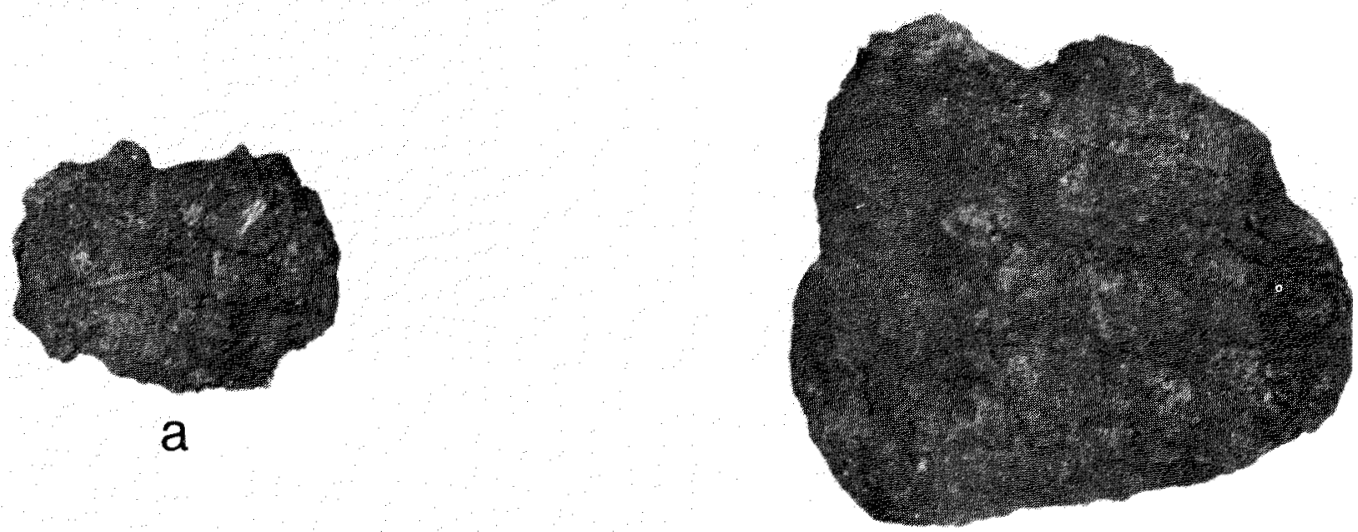

b

FIG. 7. a) A flat piece of iron located in the central floor area of house 4. An analysis of the metal gave the following results: $\mathrm{Fe} 100.4, \mathrm{Ni}<0.06$ and $\mathrm{Cu}<0.19$. b) A flat piece of iron located on top of one of the stones outlining the meat pit in house ruin 6 . An analysis of the metal gave the following results: $\mathrm{Fe} 99.9, \mathrm{Ni}<0.06$ and $\mathrm{Cu}<0.19$. See radiocarbon date for figure $2 \mathrm{a}, 670 \pm 110$ B.P.
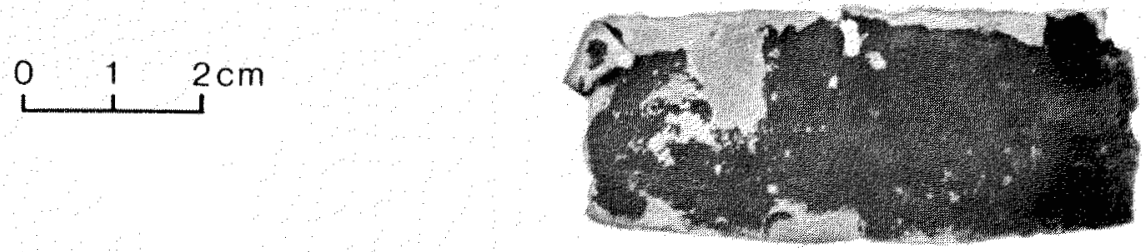

b

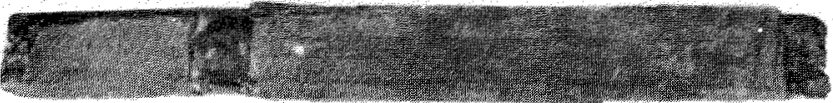

a

FIG. 8. a) A thin copper strip inset in a section of wood located on the central floor of house ruin 4. b) A copper band section located in test unit 1, house ruin 7. An x-ray fluorescence analysis at the Canadian Conservation Institute indicated the presence of copper and silver with traces of iron, antimony and possibly arsenic and selenium. A metal analysis at The University of Calgary gave the following results: $\mathrm{Fe}<0.03$, Ni 0.07 and $\mathrm{Cu}$ 99.4. 

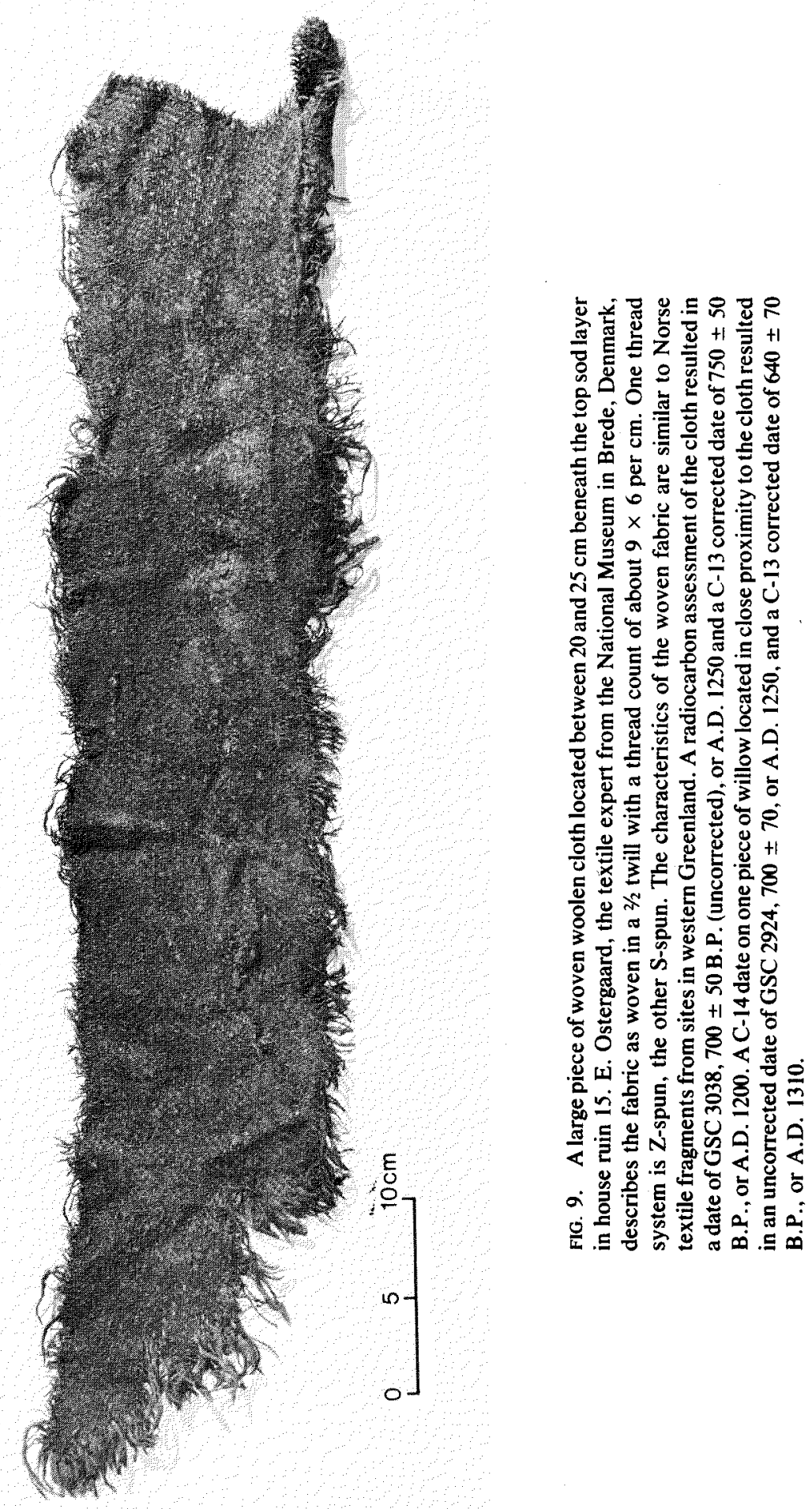

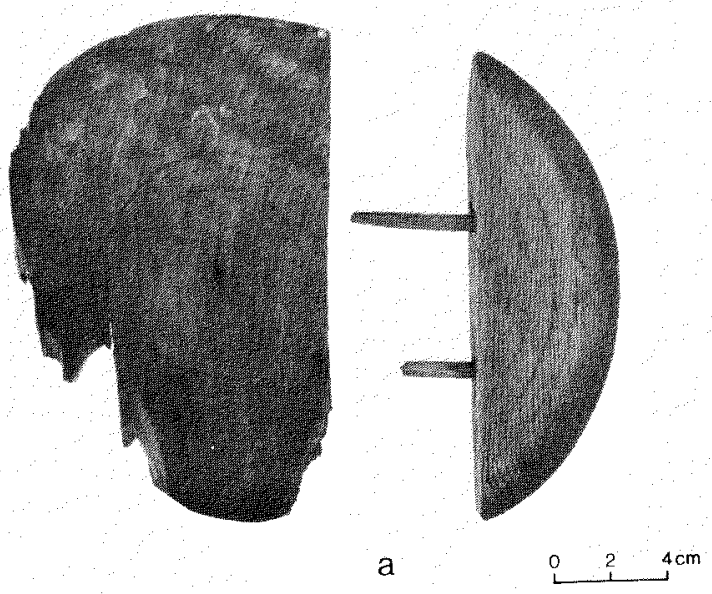

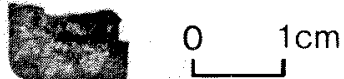

b

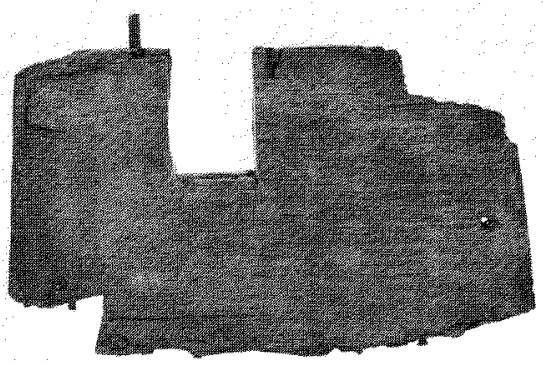

C

FIG. 10. a) Two sections of barrel bottoms secondarily joined, and decorated with a series of incised concentric circles. The joined sections were located on the floor of the entrance passage of house ruin 1 at Eskimobyen. b) A small thin copper piece located near the front edge of the sleeping platform in house ruin 1. An x-ray fluorescence analysis at the Canadian Conservation Institute indicated the presence of copper, silver, lead and antimony. A metal analysis at The University of Calgary gave the following results: $\mathrm{Fe} 0.03, \mathrm{Ni} 0.07, \mathrm{Cu} 98.7$. A radiocarbon assessment on heather from the sleeping platform in house 1 resulted in a date of GSC 2953, $610 \pm 50$ B.P. (C-13 corr.), or A.D. 1340. A second $\mathrm{C}-14$ assessment on willow from the central floor area of the house resulted in a date of GSC $2796,970 \pm 120$ B.P. (C-13 corr.), or A.D. 980 . House ruin 1 is thought to have been occupied during the early and subsequently the middle stage of the Thule culture period. c) A piece of oak wood with inset wooden dowels which appears to have been part of a box. The specimen was located on the floor of house ruin 3. A radiocarbon assessment on a section of the wood resulted in the following date: GX 6073, $560 \pm 120$ B.P. (uncorrected), or A.D. 1390. Two C-14 assessments on heather from house 3 resulted in the following dates: GSC 3018, $510 \pm 70$ B.P. (uncorrected), or A.D. 1440, and GSC $2950,500 \pm 70$ B.P. (uncorrected) or $430 \pm 70$ (C-13 corr.), or A.D. 1520. 


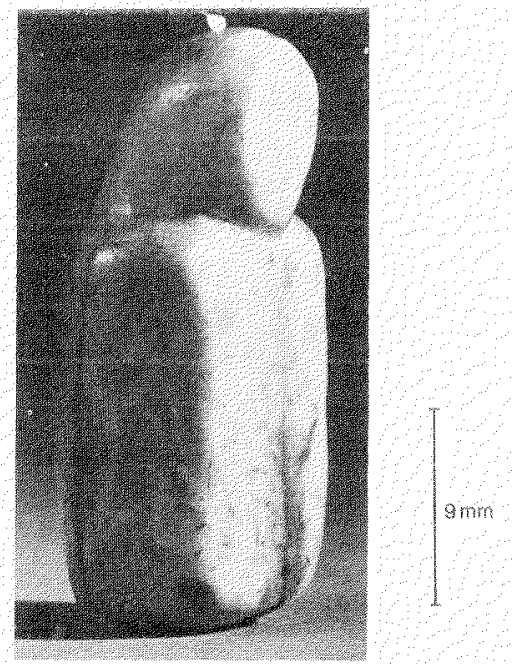

FIG. 11. A small, $27 \mathrm{~mm}$ long ivory figurine thought to represent a Norseman. The carving, which may have been produced by an Inuit, was located in house ruin 10 on Haa Island. Radiocarbon dating on heather from the sleeping platform produced the following results: GSC $2981,270 \pm 50$ B.P., (C-13 corrected), or A.D. 1680.

\section{COMMENTS}

The iron fragments presented have been subjected to $x$-ray diffraction and non-destructive $\mathrm{x}$-ray fluorescence. Further analyses were done on an ARL EMX SM electron microprobe using the pure metals as standards. Analyses were conducted at $15 \mathrm{KV}$ with a beam current of $0.2 \mu \mathrm{m}$. The analyses indicated that both terrestrial and meteoric iron fragments were represented in the artifact assemblages. Two iron pieces showed a nickel content of $6.6 \%$ and $7.0 \%$, suggesting the source area to be the Cape York meteorites (Buchwald and Graff-Petersen, 1976). The nickel content of the terrestrial iron pieces ranged between $0.06 \%$ and $0.07 \%$.

The non-diagnostic terrestrial metallic finds are thought to be of Norse origin as they were found in association with identified Norse items such as the chain mail, boat rivets, cloth, barrel and box sections.

The associated radiocarbon dates place the metal finds somewhere in the 13th to 15 th centuries A.D., well within the period of Norse activities on the west coast of Greenland. The ivory figurine (Fig. 11) is the only find which, according to the $\mathrm{C}-14$ results (approximately A.D. 1680) from house ruin 10, post-dates the demise of the Norse settlements in Greenland. The figurine could easily have been brought to Haa Island by Inuit from west Greenland. The style of house 10, with an almost linear sleeping platform arrangement and a sub-rectangular outline, is, in several attributes, similar to the Disko Bay and Labrador communal house developments between A.D. 1650 and 1700 (Petersen, 1974; Schledermann, 1976a, b). 
Artifacts of Norse origin have been located in several other High Arctic locations. Holtved (1944) found several Norse items, including a piece of woolen cloth and chain mail, on Ruin Island, directly east of the Bache Peninsula region. In 1977, on the west coast of Ellesmere Island, Sutherland (n.d.) located a section of a small folding balance, and several bronze fragments have been found in Thule culture winter house ruins on Bathurst, Devon (McGhee, 1976) and Cornwallis Islands (McGhee, n.d.). In addition to these finds, Knuth (1952) identified an oak section on an umiaq frame in northeast Greenland, which later dated to $730 \pm 100$ B.P. (K. 1449 uncorrected). A radiocarbon date (K. 1489, $680 \pm 100$ B.P.) on the woolen cloth from Ruin Island (Knuth, pers. comm.) is remarkably close to the $700 \pm 50$ B.P. date on the woolen cloth from Skraeling Island (Fig. 9).

The obvious question is whether the Norse finds arrived on the east coast of Ellesmere Island as a result of 1) direct trade between the resident Inuit and Norse explorers, or 2) trade between Inuit groups along the west coast of Greenland and across Smith Sound. Based on the present evidence it seems possible that both events took place, although more supportive evidence must be obtained in order to confirm the first contention.

One important element of the current research is a study of radiocarbon assessments processed on different materials within individual house structures. This work, under the direction of W. Blake Jr. of the Geological Survey of Canada, is providing us with a greater appreciation of the potential errors in age determination caused by the use of various datable materials. A better understanding of these factors is an essential ingredient in a discussion of the history of the Norse finds. Only a careful comparison between the C-14 determinations of the Norse items and the associated dwelling features will make it possible to determine a more exact time frame for this possible contact period. The age determinations of woolen cloth and oak pieces only indicate an approximate time of the initial shearing of wool and the cutting of an oak tree somewhere, possibly far removed in time from the appearance of these items in the Smith Sound and Kane Basin region. A comparison of willow and heather dates from the house ruins indicates a relatively older age for willow (possibly caused by the initial gathering of old, dead willow for the fire hearth) with the younger heather dates probably reflecting the use of fresh heather for sleeping platform cover.

Norse exploration and trading voyages along the coast of west Greenland are known to have taken place at least as far north as $72^{\circ}$ latitude. Undoubtedly further investigation will extend the northern range of Norse voyagers, perhaps as far as the Smith Sound/Kane Basin region.

\section{ADDENDUM}

The 1980 field season in the Bache Peninsula region produced additional items of probable Norse origin including: boat rivets, small woven woolen bag, iron spike and knife blade, many iron pieces and a copper end blade. 


\section{ACKNOWLEDGEMENTS}

I wish to thank Dr. I. Hutcheon, Dr. J. Nicholls and Mrs. M. Stout of The University of Calgary, for their analyses of the metal objects. Preliminary analyses were provided by Ms. M. Laver, Canadian Conservation Institute. An analysis of the woolen cloth was kindly provided by Mrs. E. Østergaard, National Museum, Brede, Denmark. Particular thanks to Dr. W. Blake Jr., Geological Survey of Canada for providing the radiocarbon assessments. Sincere appreciation to Dr. L. V. Hills, The University of Calgary, and Mrs. G. Møller, Danish National Museum for their assistance with the conservation procedures. Field research support has been provided by the Social Sciences and Humanities Research Council of Canada. The Arctic Institute of North America. Polar Continental Shelf Project, the National Geographic Society and the Royal Canadian Mounted Police.

\section{REFERENCES}

BUCHWALD, V. F. and GRAFF-PETERSEN, P. 1976. Catalogue of Meteorites in the Geological Museum of the University of Copenhagen. Geologisk Museum, København. Analecta Geologica 4.

HOLTVED, E. 1944. Archaeological investigations in the Thule District: Part I. Meddelelser om Grønland 141(1). 308pp.

KNUTH, E. 1952. An outline of the archaeology of Peary Land. Arctic 5(1): 17-33.

McGHEE, R. 1976. Paleoeskimo occupations of central and high arctic Canada. In: Maxwell, Moreau S. (ed.) Eastern Arctic Prehistory: Paleoeskimo Problems. Memoirs of the Society for American Archaeology 31. Washington. 15-39.

PETERSEN, R. 1974/75. Some considerations concerning the Greenland longhouse. Folk 16-17:17788.

SCHLEDERMANN, P. 1976a. The effect of climatic/ecological changes on the style of Thule culture winter dwellings. Arctic and Alpine Research 8(1):37-47.

1976b. Thule culture communal houses in Labrador. Arctic 29(1):27-37.

. Preliminary results of archaeological investigations in the Bache Peninsula region, Ellesmere Island, N.W.T. Arctic 31(4):459-474. 